\title{
Scolicidal Effects of Gallic Acid, One of the Major Compounds of Plants, on Protoscolices of Hydatid Cyst
}

\author{
Sara Larki ${ }^{1,}{ }^{*}$ Mohammad Hosein Razi Jalali, ${ }^{1}$ and Saeed Goodarzi ${ }^{2}$ \\ ${ }^{1}$ Parasitology Department, Faculty of Veterinary Medicine, Shahid Chamran University of Ahvaz, Ahvaz, IR Iran \\ ${ }^{2}$ Faculty of Veterinary Medicine, Shahid Chamran University of Ahvaz, Ahvaz, Iran \\ "Corresponding author: Sara Larki, Faculty of Veterinary Medicine, Shahid Chamran University of Ahvaz, Golestan Street, 61357-43337, IR Iran. Tel: +98-6133330011-5241, E-mail: \\ s.larki@scu.ac.ir
}

Received 2016 November 24; Revised 2017 March 27; Accepted 2017 April 22.

\begin{abstract}
Background: Today's, the recurrent of hydatidosis remain as a concern in many surgeries. Exposure of a suitable effective scolicidal agent with protoscolex-rich fluid can prevent these complications. In recent studies more have been considered to importance of natural products particularly herbal medcines to evaluate their scolicidal effects. Gallic acid a type of organic acid is one of the main known effective biological phenolic substances of plants.

Objectives: The aim of this study was to evaluate the effect of Gallic acid on protoscolices of hydatid cysts in in vitro.

Methods: In this experimental study, the protoscolices were obtained from liver hydatid cysts of infected sheep. Gallic acid solution was used at the concentration of 25,30 and $35 \mathrm{mg} / \mathrm{mL}$ for 1, 3, and 5 minutes. The live protoscolices were detected by $0.1 \%$ eosin dye. Data analysis was performed by SPSS version 11.5 and one-way ANOVA test.

Results: The Gallic acid at the concentration of $25 \mathrm{mg} / \mathrm{mL}$ disabled 35.65\%, 52.21\% and $65.38 \%$ of protoscolices after 1, 3 and $5 \mathrm{~min}$ of faced time together, respectively. Also, the scolicidal rate of Gallic acid at concentration of $30 \mathrm{mg} / \mathrm{mL}$ was $29.92 \%, 63.80 \%$ and $67.76 \%$ after 1,3 and $5 \mathrm{~min}$, respectively. It was observed that concentration of $35 \mathrm{mg} / \mathrm{mL}$ Gallic acid on protoscolices caused $92.08 \%$ and $100 \%$ mortality rate of parasites after 1 and 3 minutes, respectively (compared with $9.9 \%$ in control groups).

Conclusions: The findings of present study showed that Gallic acid as an effective constituent of some herbal scolicidal agent can be considered as responsible for killing of protoscolices. However, further studies will be needed to confirm this phytochemicals active component in animal models.
\end{abstract}

Keywords: Hydatid Cyst, Gallic Acid, Protoscolices

\section{Background}

Hydatidosis or cystic echinococcosis (CE, hydatid cyst) is one of the serious silent cyclozoonotic diseases between humans and domestic animals caused by larval stage of Echinococcus granulosus [1]. This disease with worldwide distribution is more seen in Australia, South America, Mediterranean and the Middle East countries. Iran is one of the endemic areas of hydatidosis [2]. Based on WHO-IWGE (world health organization informal working group on Echinococcosis) classification thetreatmentoptions to hydatidosis include; surgery, PAIR (Puncture, Aspiration, Injection and Reaspiration), medicinal therapy and watch and wait techniques $[3,4]$. Both surgery as preferred method and PAIR techniques have been used for treatment of cystic echinococcosis as the practical options [57]. Dissemination of the live protoscolices to tissue around can have the potential risk to growth into the new cysts [8]. So, one of the main complications of many hyadatidosis surgeries and PAIR techniques is recurrence of cysts as secondary cystic echinococcosis. The spillage of cysts contents and use of insufficient scolicidal agents made to be remaining protoscolices as alive. According to different studies, the recurrence rates of disease are assessed from 4.6 to $22 \%$ [9]. Choose of a suitable effective scolicidal agent reduce the risk of spillage of protoscolex-rich fluid [10] which may reduce the recurrence rate. Alcohol, hypertonic saline and povidone iodine are the most scolicidal compounds have frequently been applied for desperation of protoscolices [11]. Also, there are various traditional medicinal herbs have been exposed to protoscolices of hydatid cysts such as Zataria multiflora [12], Rhus coriaria L. (sumac) [13], fruits of berberis (Berberis vulgaris) [14], black cumin seed (Nigella sativa) [15] and Mallotus philippinensis [16]. The natural derivatives of scolicidal plants can be responsiblefor the killing effects on protoscolices.

Gallic acid is a 3,4,5- trihydroxybenzoic acid, an organic phenolic acid compound, has been seen widely distributed in fruits and plants such as gallnuts, sumac, witch hazel, tea leaves, oak bark, grapes, blueberries, apples, flaxseeds, walnuts and watercress and other plants. Gallic acid has antioxidant [17], anticancer [18] and anti-inflammatory properties $[19,20]$. 


\section{Objectives}

Since Gallic acid is one of the major compounds of scolicidal plants with high therapeutic characteristics, present study was examined the scolicidal features of this organic compound.

\section{Methods}

\subsection{Protoscolices Preparation}

In this experimental study, protoscolices were obtained from liver hydatid cysts of suffering sheep slaughtered in slaughterhouse of Ahwaz, southwest of Iran. The contents of cyst was drained and transmitted into the glass cylindrical containers and leaved in a static place. After 30 minutes (min) the supernatant discarded and the remaining sediment contains protoscolices washed aseptically with normal saline for several times.

The live protoscolices were detected by their motility characteristics of flame cells and also the $0.1 \%$ eosin dye (eosin powder $(1 \mathrm{~g})$ in distilled water (1 lit) under light microscopy. Fifteen min after contact with stain, unstaining protoscolices to the dye were considered as alive (Figure 1), eosin dye cannot penetrate into the live cells so remained neutral while dead protoscolices were permeable to eosin staining and colored red (Figure 2) [21]. For observation of the findings of groups under microscope and imposed the blindness in this study, we invited our parasitologist colleague who had no information of grouping of the experiments to count each samples. When viable protoscolices rate was above $95 \%$, that case was candidated as appropriate sample for subsequent experiments and these protoscolices were kept in normal saline at $4^{\circ} \mathrm{C}$ for later use.

\subsection{Preparation of Gallic Acid Solutions}

Gallic acid powder was provided by Sigma-Aldrich (St. Louis, MO). Different concentrations of Gallic acid dissolve slowly in distilled water. To access steady solution, the containers of suspension solution were placed into water bath up $40-50^{\circ} \mathrm{C}$.

\subsection{Scolicidal Tests}

In this laboratory experimental study, three concentrations $(25,30$ and $35 \mathrm{mg} / \mathrm{mL}$ ) of Gallic acid solutions were examined in parallel groups for 1, 3 and 5 minutes. $500 \mathrm{mi}$ croliter of Gallic acid solution was poured in a microtube; then with an equal volume of enriched protoscolices was blended slowly. After spending the designed times (1,3, and 5 minutes) at room temperature, the supernatant of the solution threw away with pipetting without any confusion of sediment. To stop the reaction of the residual Gallic acid

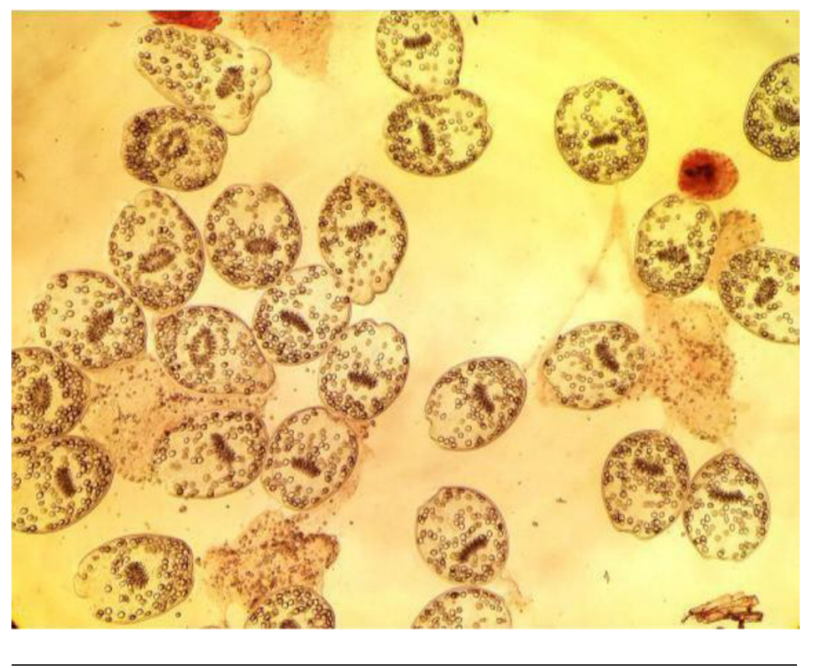

Figure 1. Viable Protoscolices in the Presence of 0.1\% Eosin Dye in Control Groups

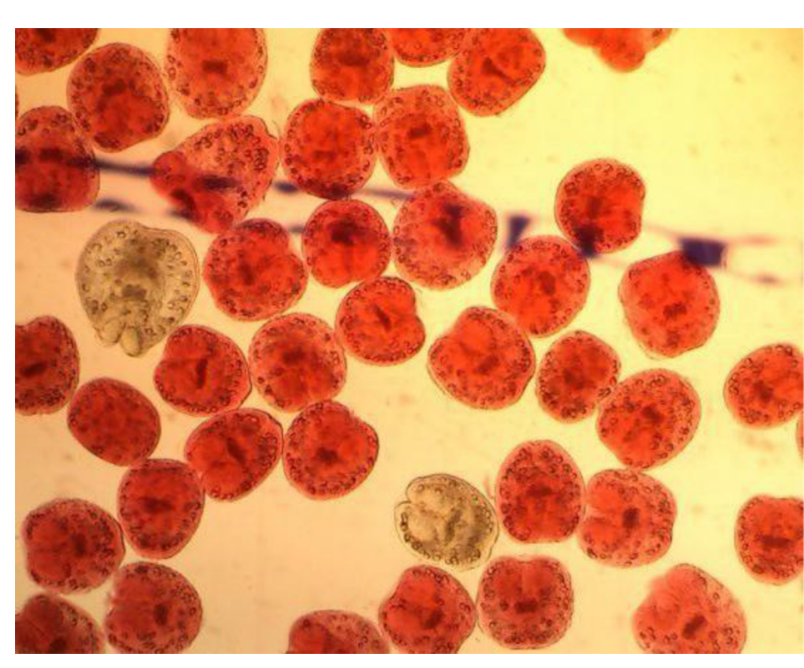

Figure 2. Colored Protoscolices Died After Effect of Various Concentrations of Gallic Acid and 0.1\% Eosin

on protoscolices, rinse with normal saline step was done. Then, the contents of microtube were reached to $1 \mathrm{~mL}$ by adding normal saline and the same volume of dye was added to the test microtube and blended slowly. 15 minutes later, the remaining sediment protoscolices was prepared smear and evaluated under a light microscope. The mortality rate of protoscolices was calculated by counting the minimum of 500 protoscolices.

The experiments were performed in triplicate. In addition, in control groups, normal saline was used during of experiment instead of Gallic acid and the results were recorded in all experiments. 


\subsection{Statistical Analysis}

All statistical analysis was performed by SPSS version 11.5 package. Differences between the test and control groups were performed by one-way ANOVA test. The significant data were determined when the $\mathrm{p}$ values were less than 0.05 .

\section{Results}

The mortality rate of protoscolices in faced to various concentrations of Gallic acid in various exposure times are presented in Tables 1, 2 and 3 while this rate in control groups were 9.9\%. The scolicidal activity of Gallic acid solution in $25 \mathrm{mg} / \mathrm{mL}$ was $35.65 \%, 52.21 \%$ and $65.38 \%$ after 1,3 and 5 minutes of exposure time, respectively. The mortality rate of Gallic acid solution in $30 \mathrm{mg} / \mathrm{mL}$ was $29.92 \%, 63.80 \%$ and $67.76 \%$ after 1,3 and 5 minutes of exposure time, respectively. When protoscolices were exposed to Gallic acid solution at concentration of $35 \mathrm{mg} / \mathrm{mL}$, increased mortality rate observed to $92.08 \%$ and $100 \%$ after 1 and 3 minutes, respectively. The protoscolicidal effect of Gallic acid solution was significant against to the control groups at all exposure times $(\mathrm{P}<0.05)$.

\section{Discussion}

In present study, the scolicidal activity of Gallic acid solution in $35 \mathrm{mg} / \mathrm{mL}$ was $92.08 \%$ and $100 \%$ after 1 and 3 minutes of exposure times, respectively, so the scolicidal property of some plants can be attributed to this major compound of plants. Today's, nevertheless of efforts and progress in therapeutic managements of hydatid cyst, cystic echinococcosis has known as an emerging or reemerging disease, yet and caused public health concerns in several countries [22].

Although various synthetic protoscolicidal solutions have been applied in surgery and PAIR techniques to inactivate the cysts contents, recurrence of disease was seen. Loss of efficacy and effectiveness of scolicidal agents, rate of adverse reactions, relapse rate and cost of agents were caused the concern of this disease continues [3]. Although formalin as the most frequently used agent $[8,23]$ povidone-iodine [24], alcohol [25], hypertonic saline 10\% $20 \%[8,23], \mathrm{H}_{2} \mathrm{O}_{2}[10]$ and cetrimide [8] investigated as effective scolicidal agents in various studies [26], but some complication and adverse side effects following the use of these scolicidal agents were reported. On the other hand species resistance to antimicrobial synthetic anthelmintic, the appearance some side effects and insufficient effectiveness of chemical scolicidal agents stimulate the research of natural alternative therapies [27]. Since the past decades, the use of natural compounds derived from plant has been frequently seen in traditional remedies [10]. Various investigations have examined the scolicidal effects of essential oils or extracts of plants in today's climate [12, 21, 28-31].

Phenolic compounds are one of the most widely occurring groups of phytochemicals which play a significant role in reproduction and growth of plants and also act as protection mechanisms against microorganisms such as parasites and predators [32]. Various bioactivities of natural phenolic compounds possess some chemopreventive properties such as antioxidant, anticancer, antibacterial, antiviral and anti-inflammatory activities [32-35].

Phenolic compound found in some scolicidal agents such as Satureja khuzistanica essential oils [36], Peganum harmala [29], garlic [21], ginger oil (Zingiber officinale) [30], Berberis vulgaris L. [31], aqueous extracts of Olea europaea leaves [37], methanolic fruit powder extract of Mallotus philippinensis [16], extract of Cardaria draba (L.) [38]. ajowan (Trachyspermum ammi L.) essential oil [39], Lepidium sativum essential oil [40], sumac (Rhus coriaria) [13, 41], Sambucus ebulus $[28,42]$.

Gallic acid a type of phenolic acids which are the main class of phenolic compounds that frequently arising in plant kingdom [43]. This organic acid is one of the main biological effective phenolic compounds of plant sources [44].

In many investigations on herbal scolicidal agents, Gallic acid is one of the main constituents have been recognized by gas chromatography and massspectroscopy analysis of scolicidal plants such as methanolic extract of sumac (Rhus coriaria) (50 mg/mL after 10 minutes) [13], Berberis vulgaris aqueous and hydro-alcohol extract (in 4 $\mathrm{mg} / \mathrm{mL}$ and $2 \mathrm{mg} / \mathrm{mL}$ after 5 minutes, respectively) [14], methanolic extract of Zataria multiflora $(25 \mathrm{mg} / \mathrm{mL}$ after 1 minute) [12], the essential oil of black cumin seed (Nigella sativa) seed (at $10 \mathrm{mg} / \mathrm{mL}$ after 10 minutes) [15], methanolic fruit powder extract of Mallotus philippinensis $(20 \mathrm{mg} / \mathrm{mL}$ for only 10 minutes treatment) [16] and Sambucus ebulus fruit extract (100 mg/mL after 60 minutes) [28, 42].

This in vitro study showed that Gallic acid is an effective scolicidal agent and can be introduced as one of the lethal factors of protoscolices. Niho et al. (2001) showed that Gallic acid is a no- observed-adverse-effect level (NOAEL) in rats [45], so can be partly safe substance. According to the antimicrobial mechanism of Gallic acid was described by Neild and Kotecha (1990), this active compound of plants altered the membrane characteristics of pathogens and reduction of negative surface charge irremeably followed by rupture or pore created in place of cell membranes and intracellular contents were discharged [46].

Further investigations will be required to isolate and examine the other active compounds of scolicidal plants 
Table 1. Scolicidal Effect of Galli cacid in Concentration of $25 \mathrm{mg} / \mathrm{mL}$ at Different Exposure Times

\begin{tabular}{|c|c|c|c|c|}
\hline Exposure Time, min & Expriments & Protoscolices & Dead Protoscolices & Mortality Rate, \% \\
\hline \multirow{4}{*}{1} & 1 & 600 & 228 & 38 \\
\hline & 2 & 521 & 165 & 31.66 \\
\hline & 3 & 500 & 185 & 37 \\
\hline & Total & 1621 & 578 & 35.65 \\
\hline \multirow{4}{*}{3} & 1 & 700 & 340 & 48.57 \\
\hline & 2 & 500 & 254 & 50.8 \\
\hline & 3 & 700 & 398 & 56.85 \\
\hline & Total & 1900 & 992 & 52.21 \\
\hline \multirow{4}{*}{5} & 1 & 611 & 408 & 66.77 \\
\hline & 2 & 500 & 305 & 61 \\
\hline & 3 & 553 & 375 & 67.81 \\
\hline & Total & 1664 & 1088 & 65.38 \\
\hline Control & & 1000 & 99 & 9.9 \\
\hline
\end{tabular}

Table 2. Scolicidal Effect of Gallic Acid in Concentration of $30 \mathrm{mg} / \mathrm{mL}$ at Different Exposure Times

\begin{tabular}{|c|c|c|c|c|}
\hline Exposure Time, min & Expriments & Protoscolices & Dead Protoscolices & Mortality Rate,\% \\
\hline \multirow{3}{*}{1} & 1 & 697 & 206 & 29.55 \\
\hline & 2 & 1000 & 311 & 31.10 \\
\hline & Total & 2252 & 674 & 29.92 \\
\hline \multirow{4}{*}{3} & 1 & 1000 & 598 & 59.80 \\
\hline & 2 & 685 & 471 & 68.75 \\
\hline & 3 & 520 & 338 & 65 \\
\hline & Total & 2205 & 1407 & 63.80 \\
\hline \multirow{4}{*}{5} & 1 & 700 & 497 & 71 \\
\hline & 2 & 1073 & 710 & 66.16 \\
\hline & 3 & 504 & 336 & 66.66 \\
\hline & Total & 2277 & 1543 & 67.76 \\
\hline Control & & 1000 & 99 & 9.9 \\
\hline
\end{tabular}

Table 3. Scolicidal Effect of Gallic Acid in Concentration of $35 \mathrm{mg} / \mathrm{mL}$ at Different Exposure Times

\begin{tabular}{|c|c|c|c|c|}
\hline Exposure Time, min & Expriments & Protoscolices & Dead Protoscolices & Mortality Rate, \% \\
\hline \multirow{4}{*}{1} & 1 & 700 & 645 & 92.14 \\
\hline & 2 & 728 & 692 & 95.05 \\
\hline & 3 & 618 & 547 & 88.51 \\
\hline & Total & 2046 & 1884 & 92.08 \\
\hline \multirow{4}{*}{3} & 1 & 531 & 531 & 100 \\
\hline & 2 & 650 & 650 & 100 \\
\hline & 3 & 610 & 610 & 100 \\
\hline & Total & 1791 & 1791 & 100 \\
\hline Control & & 1000 & 99 & 9.9 \\
\hline
\end{tabular}

to comprehend of performance evaluation of traditional medicine and produce pharmaceutical compounds. The results of present study can confirm by investigating scolicidal effect of Gallic acid in an in vivo model.

\section{Acknowledgments}

The authors would like to thank research council of Shahid Chamran University of Ahvaz, Iran, for the financial support (Code: 80456). 


\section{Footnotes}

Authors' Contribution: All authors had equal role in design, work, statistical analysis and manuscript writing.

Funding/Support: Research council of Shahid Chamran University of Ahvaz, Iran.

\section{References}

1. Hashemi Tabar G, Haghparast A, Borji H. Serodiagnosis of sheep hydatidosis with hydatid fluid, protoscolex, and whole body of Echinococcus granulosus antigens. Comparative Clinical Pathology. 2010;21(4):429-32. doi: 10.1007/s00580-010-1112-4.

2. Sadjjadi SM. Present situation of echinococcosis in the Middle East and Arabic North Africa. Parasitol Int. 2006;55 Suppl:S197-202. doi: 10.1016/j.parint.2005.11.030. [PubMed:16337429].

3. Junghanss T, da Silva AM, Horton J, Chiodini PL, Brunetti E. Clinical management of cystic echinococcosis: state of the art, problems, and perspectives. Am J Trop Med Hyg. 2008;79(3):301-11. [PubMed: 18784219].

4. Brunetti E, Kern P, Vuitton DA, Writing Panel for the W. Expert consensus for the diagnosis and treatment of cystic and alveolar echinococcosis in humans. Acta Trop. 2010;114(1):1-16. doi: 10.1016/j.actatropica.2009.11.001. [PubMed: 19931502].

5. Yorganci K, Sayek I. Surgical treatment of hydatid cysts of the liver in the era of percutaneous treatment. Am J Surg. 2002;184(1):63-9. [PubMed: 12135724].

6. Akhan O, Ozmen MN. Percutaneous treatment of liver hydatid cysts. Eur J Radiol. 1999;32(1):76-85. [PubMed:10580324].

7. Canyigit M, Gumus M, Cay N, Erol B, Karaoglanoglu M, Akhan O. Refractory cystobiliary fistula secondary to percutaneous treatment of hydatid cyst: treatment with N-butyl 2-cyanoacrylate embolization. Cardiovasc Intervent Radiol. 2011;34 Suppl 2:S266-70. doi: 10.1007/s00270-009-9790-5. [PubMed: 20054546].

8. Besim H, Karayalcin K, Hamamci O, Gungor C, Korkmaz A. Scolicidal agents in hydatid cyst surgery. HPB Surg. 1998;10(6):347-51. [PubMed: 9515230].

9. Prousalidis J, Kosmidis C, Anthimidis G, Kapoutzis K, Karamanlis E, Fachantidis E. Postoperative recurrence of cystic hydatidosis. Can J Surg. 2012;55(1):15-20. doi: 10.1503/cjs.013010. [PubMed: 21939605].

10. Adas G, Arikan S, Kemik O, Oner A, Sahip N, Karatepe O. Use of albendazole sulfoxide, albendazole sulfone, and combined solutions as scolicidal agents on hydatid cysts (in vitro study). World J Gastroenterol. 2009;15(1):112-6. [PubMed: 19115476].

11. Karaoglanoglu M, Akinci OF, Ulukanligil M, METIN MR, CETIN H, Cay N. Hydatid cyst viability: the effect of scolicidal agents on the scolex in the daughter cyst. Turk J Med Sci. 2011;41(6):1001-6.

12. Moazeni M, Roozitalab A. High scolicidal effect of Zataria multiflora on protoccoleces of hydatid cyst: an in vitro study. Compar Clin Pathol. 2010;21(1):99-104. doi:10.1007/s00580-010-1069-3.

13. Moazeni M, Mohseni M. Sumac (\&lt;i\&gt;Rhus coriaria\&lt;/i\&gt; L.): Scolicidal Activity on Hydatid Cyst Protoscolices. Surg Sci. 2012;03(09):452-6. doi:10.4236/ss.2012.39089.

14. Salehi N, Rouhani S, Kamalinejad M, Zayeri F, Motaghifar A. Scolicidal effects of Berberis vulgaris fruit extract on hydatid cyst protoscolices. Tehran Univ Med J TUMS Public. 2014;72(2):121-8.

15. Mahmoudvand H, Dezaki ES, Kheirandish F, Ezatpour B, Jahanbakhsh S, Harandi MF. Scolicidal effects of black cumin seed (Nigella sativa) essential oil on hydatid cysts. Korean J Parasitol. 2014;52(6):653-9. doi: 10.3347/kjp.2014.52.6.653. [PubMed: 25548417].

16. Gangwar M, Verma VC, Singh TD, Singh SK, Goel RK, Nath G. Invitro scolicidal activity of Mallotus philippinensis (Lam.) Muell Arg. fruit glandular hair extract against hydatid cyst Echinococcus granulosus. Asian Pac J Trop Med. 2013;6(8):595-601. doi: 10.1016/S19957645(13)60103-0. [PubMed: 23790329].
17. Asnaashari M, Farhoosh R, Sharif A. Antioxidant activity of gallic acid and methyl gallate in triacylglycerols of Kilka fish oil and its oil-in-water emulsion. Food Chem. 2014;159:439-44. doi: 10.1016/j.foodchem.2014.03.038. [PubMed: 24767079].

18. Maurya DK, Nandakumar N, Devasagayam TP. Anticancer property of gallic acid in A549, a human lung adenocarcinoma cell line, and possible mechanisms. J Clin Biochem Nutr. 2011;48(1):85-90. doi: 10.3164/jcbn.11-004FR. [PubMed: 21297918].

19. Kroes BH, van den Berg AJ, Quarles van Ufford HC, van Dijk H, Labadie RP. Anti-inflammatory activity of gallic acid. Planta Med. 1992;58(6):499-504. doi:10.1055/s-2006-961535. [PubMed: 1336604].

20. Locatelli C, Filippin-Monteiro FB, Ariana C. In: Handbook onGallic acid: Natural Occurrences, Antioxidant Properties and Health Implications. Thompson MA, Collins PB, editors. Hauppauge: Nova science publishers; 2013. pp. 1-23.Antioxidant, Antitumoral and Anti Inflammatory Activities of GA.

21. Moazeni M, Nazer A. In vitro effectiveness of garlic (Allium sativum) extract on scolices of hydatid cyst. ;34(11):2677-81.

22. Moro P, Schantz PM. Echinococcosis: a review. Int J Infect Dis. 2009;13(2):125-33. doi: 10.1016/j.ijid.2008.03.037. [PubMed: 18938096].

23. Topcu O, Aydin C, Arici S, Duman M, Koyuncu A, Sen M. The Effects of Various Scolicidal Agents on the Hepatopancreatic Biliary System. Viscer Med. 2006;22(3):185-90. doi: 10.1159/000094710.

24. LeVeen HH, LeVeen RF, LeVeen EG. The mythology of povidone-iodine and the development of self-sterilizing plastics. Surg Gynecol Obstet. 1993;176(2):183-90. [PubMed: 8421809].

25. Yetim I, Erzurumlu K, Hokelek M, Baris S, Dervisoglu A, Polat C, et al. Results of alcohol and albendazole injections in hepatic hydatidosis: experimental study. J Gastroenterol Hepatol. 2005;20(9):1442-7. doi: 10.1111/j.1440-1746.2005.03843.x. [PubMed: 16105134].

26. Kilicoglu B, Kismet K, Kilicoglu SS, Erel S, Gencay O, Sorkun K, et al. Effects of honey as a scolicidal agent on the hepatobiliary system. World J Gastroenterol. 2008;14(13):2085-8. [PubMed:18395911].

27. Harris JC, Plummer S, Turner MP, Lloyd D. The microaerophilic flagellate Giardia intestinalis: Allium sativum (garlic) is an effective antigiardial. Microbiology. 2000;146 Pt 12:3119-27. doi: 10.1099/00221287146-12-3119. [PubMed: 11101670].

28. Gholami SH, Rahimi-Esboei B, Ebrahimzadeh MA, Pourhajibagher M. In vitro effect of Sambucus ebulus on scolices of Hydatid cysts. Eur Rev Med Pharmacol Sci. 2013;17(13):1760-5. [PubMed: 23852900].

29. Hammoshi MH, Shareef AY, Younis GT. Effect of Ethanolic Extract and Crude Alkaloides of Peganum harmala Seeds on The Viability of Echinococcus granulosus Protoscolices in vitro. Raf Jour Sci. 2005;16(6):1-8.

30. Feizi F, Moradkhani S, Matini M, Parandin F, Roushan A, Fallah M. To Study the Solicidal Effects of the Extracts of Ginger (Zingiber officinale) and Artemisia (Artemisia aucheri) on Protoscoleces of Hydratid Cyst in vitro. AMUJ. 2015;18(101):45-52.

31. Rouhani S, Salehi N, Kamalinejad M, Zayeri F. Efficacy of Berberis vulgaris aqueous extract on viability of Echinococcus granulosus protoscolices. J Invest Surg. 2013;26(6):347-51. doi: 10.3109/08941939.2013.818746. [PubMed: 23978263].

32. Baidez AG, Gomez P, Del Rio JA, Ortuno A. Dysfunctionality of the xylem in Olea europaea L. Plants associated with the infection process by Verticillium dahliae Kleb. Role of phenolic compounds in plant defense mechanism. J Agric Food Chem. 2007;55(9):3373-7. doi: 10.1021/jf063166d. [PubMed: 17394331].

33. Han X, Shen T, Lou H. Dietary Polyphenols and Their Biological Significance. Int J Mol Sci. 2007;8(9):950-88. doi:10.3390/i8090950.

34. Veeriah S, Kautenburger T, Habermann N, Sauer J, Dietrich H, Will F, et al. Apple flavonoids inhibit growth of HT29 human colon cancer cells and modulate expression of genes involved in the biotransformation of xenobiotics. Mol Carcinog. 2006;45(3):164-74. doi: 10.1002/mc.20158. [PubMed: 16369997]. 
35. Owen RW, Giacosa A, Hull WE, Haubner R, Spiegelhalder B, Bartsch $\mathrm{H}$. The antioxidant/anticancer potential of phenolic compounds isolated from olive oil. Eur J Cancer. 2000;36(10):1235-47. [PubMed: 10882862].

36. Moazeni M, Saharkhiz MJ, Hoseini AA, Alavi AM. In vitro scolicidal effect of Satureja khuzistanica (Jamzad) essential oil. Asian Pac J Trop Biomed. 2012;2(8):616-20. doi:10.1016/s2221-1691(12)60107-5.

37. Ryan D, Antolovich M, Prenzler P, Robards K, Lavee S. Biotransformations of phenolic compounds in Olea europaea L. Scientia Horticulturae. 2002;92(2):147-76.

38. Sharifi-Rad J, Hoseini-Alfatemi S, Sharifi-Rad M, Teixeira da Silva J, Rokni M, Sharifi-Rad M. Evaluation of Biological Activity and Phenolic Compounds of Cardaria draba (L.) Extracts. J Biol Today's World. 2015;4(9) doi: 10.15412/j.jbtw.01040901.

39. Chatterjee S, Goswami N, Bhatnagar P. Estimation of Phenolic Components and in vitro Antioxidant Activity of Fennel (Foeniculum vulgare) and Ajwain (Trachyspermum ammi) seeds. Adv Biores. 2012;3(2):109-18.

40. Bahrami S, Razi Jalali MH, Ramezani Z, Pourmehdi Boroujeni M, Toeimepour F. In vitro Scolicidal Effect of Lepidium sativum Essential
Oil. J Ardabil Univ Med Sci. 2016;15(4):395-403.

41. Kosar M, Bozan B, Temelli F, Baser KHC. Antioxidant activity and phenolic composition of sumac (Rhus coriaria L.) extracts. Food Chem 2007;103(3):952-9. doi: 10.1016/j.foodchem.2006.09.049.

42. Karami M, Ale-Nabi SS, Nosrati A, Naimifar A. The protective effect of Sambucus ebulus against lung toxicity induced by gamma irradiation in mice. Pharm Biomed Res. 2015;1(1):48-54. doi: 10.18869/acadpub.pbr.1.1.48.

43. Cai Y, Luo Q, Sun M, Corke H. Antioxidant activity and phenolic compounds of 112 traditional Chinese medicinal plants associated with anticancer. Life Sci. 2004;74(17):2157-84. doi: 10.1016/j.lfs.2003.09.047. [PubMed: 14969719].

44. Karamac M, Kosinska A, Pegg RB. Content of gallic acid in selected plant extracts. Polish J Food Nutr Sci. 2006;15(1):55.

45. Niho N, Shibutani M, Tamura T, Toyoda K, Uneyama C, Takahashi N, et al. Subchronic toxicity study of gallic acid by oral administration in F344 rats. Food Chem Toxicol. 2001;39(11):1063-70. [PubMed:11527565].

46. Neild TO, Kotecha N. Actions of neuropeptide Y on arterioles of the guinea-pig small intestine are not mediated by smooth muscle depolarization. J Auton Nerv Syst. 1990;30(1):29-35. [PubMed: 2348052] 